\title{
Best Practices for Inclusivity of Deaf/deaf/Hard of Hearing Students in the Synchronous Online Classroom
}

\author{
Elisabeth A. Counselman Carpenter ${ }^{1, *}$, Ariel Meltzer ${ }^{2} \&$ Matthea Marquart ${ }^{3}$ \\ ${ }^{1}$ Department of Social Work, Southern Connecticut State University, 101 Farnham Avenue, New Haven, CT 06515, \\ USA \\ ${ }^{2}$ Social Worker, State of New Jersey, USA \\ ${ }^{3}$ Assistant Dean of Administration, Online Campus, USA \\ *Correspondence: College of Health and Human Services, Department of Social Work, Southern Connecticut State \\ University, New Haven, CT, USA. E-mail: counselmane1@southernct.edu
}

Received: June 29, 2020

Accepted: August 6, $2020 \quad$ Online Published: August 17, 2020

doi:10.5430/wje.v10n4p26

URL: https://doi.org/10.5430/wje.v10n4p26

\begin{abstract}
This case study discusses the current gap in knowledge of how to best support Deaf/deaf/Hard of Hearing learners in online classrooms in higher education and shares important recommendations for instructors, course designers and program administrators. Written from both the student and instructor perspective, this case study explores current trends in online higher education, data on the experience of Deaf/deaf/Hard of Hearing students and current options for improving inclusivity in the online classroom as well as specific issues related to content delivery are examined. Best practices and implications for practice that address meeting the needs and improving accessibility for Deaf/deaf/Hard-of-Hearing learners are reviewed.
\end{abstract}

Keywords: online education, synchronous learning, D/d/HH graduate studies, inclusive classroom practices

\section{Introduction}

Approximately 2-3 out of 1,000 children throughout the world are identified as Deaf/deaf/Hard-of Hearing (D/d/HH) and hearing differences are identified as the third highest medical issue facing children today (NIDCD, 2016). However, current numbers related to deaf adults in education is incredibly limited and published demographics appear often quite out of date. While it is hard to pin down exactly how many Deaf students are currently enrolled in higher education, according to the National Center for Educational Statistics, $93 \%$ of the $20,000 \mathrm{D} / \mathrm{d} / \mathrm{HH}$ students enrolled in higher education are enrolled at the undergraduate level only. It does not yet appear that there is any research that currently focuses exclusively on $\mathrm{D} / \mathrm{d} / \mathrm{HH}$ students who are online learners at the graduate or post-graduate level.

Why is there such a significant research gap on $\mathrm{D} / \mathrm{d} / \mathrm{HH}$ graduate students in any type of classroom, let alone residential or virtual ones? In addition to students who are identified as $\mathrm{D} / \mathrm{d} / \mathrm{HH}$ at birth and in childhood, there is a significant number of adults who become adult through hearing loss through lifespan. Concurrently, the number of adults engaging in graduate education is also expanding, which also means that the growing number of $\mathrm{D} / \mathrm{d} / \mathrm{HH}$ students is increasing as more adults participate in graduate education. As online education continues to decrease barriers and improve access to graduate learning, how can online educators engage in inclusive practices to support $\mathrm{D} / \mathrm{d} / \mathrm{HH}$ students inside and outside of the classroom?

This case study is written from the perspective of two social work professionals participating in a fully online masters-level learning environment: the course instructor and a Deaf student and discusses the current challenges and barriers to implementing a fully inclusive online learning experience for $\mathrm{D} / \mathrm{d} / \mathrm{HH}$ students as well as suggested best practices for course design, teaching skills and implications for further research.

\section{Literature Review}

2.1 Deaf/deaf/Hard of Hearing Students in Graduate Education

Finding literature on $\mathrm{D} / \mathrm{d} / \mathrm{HH}$ students enrolled in graduate-level education is a significant challenge. There are large 
gaps in information on D/d/HH students following high school graduation (Richardson, MacLeod-Gallinger, McKee, \& Long, 2000) and the numbers that are available present a somewhat bleak picture. Marschark et al. (2002) found that only $30 \%$ of $\mathrm{D} / \mathrm{d} / \mathrm{HH}$ complete and graduate from four-year programs as compared to $70 \%$ of hearing students. From 2001-2006, only $20 \%$ of D/d/HH students attending the National and Technical Institute for the Deaf (NTID is the largest technical college in the world for $\mathrm{D} / \mathrm{d} / \mathrm{HH}$ students) reported that their goal was to obtain a graduate degree (Albertini, Kelly, \& Matchett, 2011). There are better number of associate degree programs, as thirty-five percent of $\mathrm{D} / \mathrm{d} / \mathrm{HH}$ students in graduate programs complete a 2-year program which is only is only $5 \%$ lower rates as compared to their hearing peers, but data on four year colleges, graduate or post-graduate programs is almost non-existent. This lack of success is often attributed to a combination of three factors of overall under-preparedness of $\mathrm{D} / \mathrm{d} / \mathrm{HH}$ students, specifically related to time management, preparation for the class material, and student concentration (Albertini et al., 2011).

In addition to the significant drop-off of $\mathrm{D} / \mathrm{d} / \mathrm{HH}$ students from high school to college programs and then graduate level studies, there are also linguistic challenges in how the population is defined and how data is gathered about them. One of the biggest issues is that there remains a lack of universal terminology used to describe $\mathrm{D} / \mathrm{d} / \mathrm{HH}$ engaged in online learning. The terms that appear in current and past research include a variety of outdated and offensive terms such as "mute", "hearing impaired", "disabled", and "handicapped". These terms are not only incredibly marginalizing but the lack of universally accepted terms to describe $\mathrm{D} / \mathrm{d} / \mathrm{HH}$ learners is also problematic. The appropriate terminology is Deaf/deaf/Hard of Hearing, which is considered the most appropriate and inclusive term for the entire community. The capital D in "Deaf" denotes a Deaf person who identifies as culturally Deaf and may or may not hear some sounds and/or speak on some and/or all levels and the lowercase $d$ in "deaf" represents a deaf person who may identify most as medically deaf but not culturally Deaf. An individual who identifies as Hard of Hearing may identify most with hearing some sounds and/or speaking on some and/or all levels and/or may not identify with Deaf or deaf. For the purposes of this paper, the abbreviation $\mathrm{D} / \mathrm{d} / \mathrm{HH}$ will be used.

When conducting a search inclusive of all current terminology related to $\mathrm{D} / \mathrm{d} / \mathrm{HH}$ students, the majority of studies focuses on K-12 students as opposed to college or graduate school students. The narrow lens of a K-12 perspective of the majority of research leaves a significant gap in the current research knowledge base around older and adult students that populate the graduate classroom. There is even less information available on the intersection of online or remote learning and $\mathrm{D} / \mathrm{d} / \mathrm{HH}$ students as most studies focus on the brick-and-mortar classroom. Ferreiro-Lago and Osuna-Acedo (2017) conducted a study that identified inequalities in access to online learning by $\mathrm{D} / \mathrm{d} / \mathrm{HH}$ students. When asked why they have never participated in an online course, this study found that $28 \% \mathrm{of} \mathrm{D} / \mathrm{d} / \mathrm{HH}$ students reported an overall lack of accessibility of the course, while $29 \%$ reported having a general preference for face-to-face courses (2017). In contrast, Long, Marchetti, and Fasse (2011) found that some D/d/HH students reported a preference for an online course over an in-person course. Participants shared that their reasons for this preference included having extra time to respond rather than thinking on the spot and feeling more connected with their hearing peers because they were all using written English to communicate.

\section{The Role of Technology When Working with Students with Disabilities.}

There are challenges in understanding the experience of students with disabilities and limited understanding of how to decrease barriers to success for students with disabilities in online learning. Overall research looking at the intersection of online learning and students with disabilities has found that current studies often focus on one of the four groups of stakeholders impacted in online learning: the course instructors, disability-service coordinators/providers and online learning course designers/administrators with the least frequent focus on surveying the students themselves (Fichten et al., 2004; Fichten et al., 2009). Limited specific studies that focus on students' voices, such as Roberts et al. (2011), found that students with a disability perceived that their disability had a negative impact on their online learning and other findings included strong themes that students struggled to concentrate, struggled with online testing, felt the impact of medication on processing speed and difficulties with long periods in front of a computer screen.

Research shows that information communication technologies (ICT) have expanded the way that instructors can meet the needs of students who learn differently, yet while little is still known about overall e-learning needs of students with disabilities, particularly students who are $\mathrm{D} / \mathrm{d} / \mathrm{HH}$ and few that are written from the student perspective (Abrami et. al, 2006; Fichten et al. 2009). Overall, online learning has been shown to demonstrate improved inclusion of students with disabilities. Some of the reasons are specifically related to accessibility as online learning has shown to increase access of attendance for students who may have transportation and/or accessibility needs, decreases challenges related to climate/weather conditions or the minimizes difficulties in experiencing navigation of the brick-and-mortar classroom 
(Fichten et al., 2009; Debenham, 2002; Di Iorio, Feliziani, Mirri, Salomoni, \& Vitali, 2006). The online classroom can provide greater accessibility also for the $\mathrm{D} / \mathrm{d} / \mathrm{HH}$ student. For example, in a residential classroom, Long, Vignare, Rappold, \& Mallory (2007) have noted that in traditional in-class instruction, there is a delay that occurs between the hearing professor and the American Sign Language interpreter, which may cause students to feel out of sync when asking the hearing professor a question and/or answering a question given to the $\mathrm{D} / \mathrm{d} / \mathrm{HH}$ student by the hearing professor. $\mathrm{D} / \mathrm{d} / \mathrm{HH}$ students may also feel isolated and/or left out from their hearing peers due to feeling that they are not being properly communicated with in class (Long et al., 2007). However, the online classroom provides many opportunities for $\mathrm{D} / \mathrm{d} / \mathrm{HH}$ students to interact, learn, and understand that may not have been present in traditional in-class instruction due the option of having a live captionist. Another strength is that online courses also deliver print material in a different format, increasing accessibility to those who experience print-based impairments.

However, with the online learning boom, there are challenges to implementation of best practices, as instructors often focus on the overall transition of the course from residential learning to online learning without considering accessibility of assignments, readings or overall course delivery (Bissonette, 2006; Fichen et al., 2009). One example of this, to be discussed later in the case study, is posting video/media clips without appropriate captioning. Another is that instructors often rely on software only with which they are familiar, simply because of this familiarity when beginning to teach in an online setting, or the administration purchases the newest model, rather than thinking about whether or not is comparable with adaptive software for students who are visually impaired or D/d/HH (Fichten et al., 2009). Factors that do improve experiences of online students who have disabilities include disclosure of one's disabilities to the university's accommodations office (Roberts et al., 2011) and that teaching presence and social presence, particularly the facilitation of relationships between online students, can lead to students' perceived learning achievement and class satisfaction (Alamri \& Tyler-Wood, 2016).

\subsection{Differences in Learning Styles for D/d/HH Students}

Limited research shows that there are differences in how $\mathrm{D} / \mathrm{d} / \mathrm{HH}$ students and hearing students approach learning material. These differences are impacted by both life experiences and the learning environment (Spencer \& Marschark, 2010). Often, $\mathrm{D} / \mathrm{d} / \mathrm{HH}$ students have their learning needs lumped in with other types of disabilities which can make it difficult to track their unique barriers to learning inclusivity and best practices for online classrooms specific to $\mathrm{D} / \mathrm{d} / \mathrm{HH}$ unique learning needs.

Regardless of learning environment, Spencer and Marschark (2010) also identify that some of the learning differences for $\mathrm{D} / \mathrm{d} / \mathrm{HH}$ students include less verbal and non-verbal recall from sequential memory span tasks and less well-developed problem-solving strategies than hearing students. Although there is an assumption that $\mathrm{D} / \mathrm{d} / \mathrm{HH}$ students are visual learners or have stronger visual learning skills and habits, Marschark, Pavio, Spencer, Durkin, Borgna, Convertino \& Machmer (2017) found this to be erroneous. D/d/HH students are no more likely than hearing students to be visual learners and are no stronger in their visual skills and habits than their verbal skills and habits, nor are $\mathrm{D} / \mathrm{d} / \mathrm{HH}$ students' visual orientations associated with sign language skills. The results clearly have specific implications for the education of deaf learners and challenges this often perpetuated and inaccurate myth.

\subsection{Micro-aggressions to Avoid in Language and Behavior}

Micro-aggressions, which are broadly defined as 'brief and subtle verbal and/or non-verbal denigrating messages' that 'ambiguously disempower' minorities (Cruz, Rodriguez, Mastropaolo, 2019), are frequently used toward D/d/HH individuals, mainly by their hearing peers in classroom settings. The co-author of this paper, [name redacted for blind review] gathered a list of the most common micro-aggressions used in the classroom, based on shared experiences among their $\mathrm{D} / \mathrm{d} / \mathrm{HH}$ peer group and colleagues as well as their own experiences as a student to compile the following table:

Table 1. Micro-aggressions to Avoid in Language and Behavior

\begin{tabular}{|c|c|c|}
\hline \multicolumn{3}{|c|}{ A List of the Most Common Micro-aggressions Used in the Classroom } \\
\hline $\begin{array}{l}\text { "Oh, you're Deaf? That's okay - you're so } \\
\text { smart!" }\end{array}$ & "You don't look Deaf" & "I don’t see you as disabled" \\
\hline "Wow, you are so inspiring!" & $\begin{array}{l}\text { "You function so well in class, I wouldn't } \\
\text { even have noticed you are Deaf!" }\end{array}$ & "How do you drive to class?" \\
\hline "So you read Braille in class?" & "But you read lips so well!" & “But you speak so well!" \\
\hline $\begin{array}{l}\text { Assumption of student accommodations } \\
\text { needed or not needed in the classroom }\end{array}$ & $\begin{array}{l}\text { "How can you understand the English on } \\
\text { exams?" }\end{array}$ & $\begin{array}{l}\text { "It must be so hard being } \\
\text { Deaf!" }\end{array}$ \\
\hline
\end{tabular}




\section{Case Study: 2 Perspectives}

4.1 Student Lens: From the Perspective of a Former Student who Attended [Name Redacted for Blind Review] Online Program from 2016-2018

Upon enrolling as a full-time Master's degree student in the field of social work, I was directed to [name redacted for blind review] disability services website where I was set up with a disability coordinator who presented me with an understanding of the services offered to $\mathrm{D} / \mathrm{d} / \mathrm{HH}$ students. Social work courses typically focus on theory, policy, research methods, and for this particular concentration a number of basic and advanced clinical courses which require the practicing of in vivo behavioral health skills and techniques. The coordinator presented the options of live C-print live-captioning services or a live ASL interpreter. I chose the first option for two reasons: English is my first language (as opposed to someone who may identify ASL as their primary language), and second, I wanted to focus primarily on using my Cochlear Implants to hear, while having the C-print captioning services as a backup. Upon entering this program, I was under the impression that I would have full access to all information in my courses, specifically with class material and content.

However, my experience was significantly different. I experienced professors and in-class technical service providers who did not realize that they have a $\mathrm{D} / \mathrm{d} / \mathrm{HH}$ student in their classroom which in turn affected various aspects of the quality of my experience as a $\mathrm{D} / \mathrm{d} / \mathrm{HH}$ learner. This included professors scrambling to make sure all of their class material/content had closed captions, knowing what it meant and how I identify as a D/d/HH person, understanding the role of the live C-Print captioner, and knowing how to speak inclusively to a $\mathrm{D} / \mathrm{d} / \mathrm{HH}$ person.

There were several occasions where I needed to contact the professor to let them know that they had posted class content on the syllabus (specifically links to podcasts and video content) which did not provide required closed captioning. The delay between when the professor honored my request by seeking closed captioning services via [name redacted for blind review] disability services and when the request was fulfilled could be anywhere from 1-2 weeks. This delay was enough to put me behind my hearing colleagues in terms of waiting for access to material/content and submitting my assignments related to course content on time. Even though professors gave me extended time to complete such assignments, I did not have equal access to my hearing colleagues, especially when assignments involved forum discussions about the non-captioned material/content which I had to wait a week or two for access. I would be behind my peers as they engaged with one another in the discussion as I waited to be provided the material. In addition, some professors asked that I personally request the material to be captioned. This is not the responsibility of the student, but the responsibility of the professor and university to make sure the needs of $\mathrm{D} / \mathrm{d} / \mathrm{HH}$ students are being met.

A secondary issue is when the C-print technology fails to work in the middle of a busy academic class. Due to the layout of the online classroom, professors are not aware when the technology stops working and it becomes the burden of the student needs to let the professor or TA know what is going on. Many times, the professor and/or TA told me to step out of class to contact the right person to fix this issue. This is not only time-consuming and distracting from academic content, but also detrimental to my learning experience since course content was missed. It was then up to me to determine just how much course material I had missed and how much I needed to catch up to move forward in the synchronous class.

In terms of the socially constructed learning environment, my hearing colleagues at CSSW were almost always unaware of how to interact and converse with a $\mathrm{D} / \mathrm{d} / \mathrm{HH}$ person. I experienced classmates attempting to talk to the live C-print captionist who was busy doing their job, ask questions in the middle of class about the C-print captionist, and ask me questions about being Deaf at inappropriate times during class. I also experienced classmates unknowingly speaking too fast/not waiting for the C-print captionist to caption. Many colleagues do not comprehend the time it between the C-print captionist to type the information being said in class and me reading said information. These experiences within CSSW demonstrate poor planning, institutional gaps, and lack of understanding of D/d/HH culture and students in online higher education.

\subsection{Instructor Lens: From One of This Student's Instructors through Our First Online Class Together}

This experience was the first time I had worked with a Deaf student in a fully online learning environment and I quickly had to figure out how to adjust course material and the online classroom setting to best support an inclusive environment for all students, but particularly this student, without any training or personal knowledge of how to do it well. At first, I was totally overwhelmed and unprepared to proceed in an inclusive manner. Here are some of the lessons I learned as being part of this transformative teaching process: 1) mindful preparation and not making assumptions, 2) utilizing and advocating for all institutional support possible, 3) building a strong working relationship 
with the student, 4) managing the classroom setting to create an inclusive environment and 5) minimizing burden.

The first step was intentionality in selecting reading/course material selection and in choosing media examples. The program was fortunate enough to have a dedicated captioning program, but the turn-around time could be up to four weeks. This meant not making any last-minute changes and thinking ahead to any and all possibility of what I wanted to assign for course materials. The extra time spent in preparation was a worthwhile investment, as it was better to have two videos to choose from that week rather than none at all. As an instructor with $\mathrm{D} / \mathrm{d} / \mathrm{HH}$ students in your classroom, it is your responsibility to stick to the lesson plan and share captioned material early, rather than swapping media out last minute and hoping the student will catch up. I also quickly learned not to assume that 'automatically captioned media' such as a TEDTalk, or personally captioned YouTube videos were accurate. Unfortunately, it took the dissemination of inaccurate information and unmet learning objectives for me to learn this lesson. The second important lesson was working with the disability resource team in terms of administrative timelines, length of media chosen, and when there was occasionally a 'rush order' needed. Understanding the limitations and time-lines of this particular administrative system created a healthier working relationship that facilitated a smoother transition of course materials.

Communicating with the student was critical to the success of the overall learning environment. As the course progressed, I learned to set aside extra moments before or after class when the captionist was present to check in about the pace of the lecture, to ask if they student wanted to communicate with ASL in their live presentation, and when we needed to meet outside of course time, to schedule around the captionist to create an inclusive office hours experience. Regular check-ins allowed both of us to communicate our needs and limitations around the fast-paced clinical material. These check-ins also allowed for space for the student to communicate about any exclusionary behavior or micro-aggressions that were occurring in class. The teaching team would also regularly mine class chat and discussion boards for micro-aggressions. Looking back on this experience, I should have met with the student prior to the launch of the course, asked them what their needs and expectations of their classmates were, and folded them into a community agreement during the first class. This would have included a general announcement that a captionist was present in the classroom and to explain the boundaries around communicating with them and some psychoeducation about the role of captionist while protecting the identity of the student.

Finally, making sure that I was not burdening the student to 'fix' any challenges within the classroom setting became critically important. Just like a brick-and-mortar classroom, it was my responsibility, along with the IT team to make sure that all of the technology was working to the best of our ability. Fortunately, this was a co-taught class, and when there was a tech emergency during live lecture, the TA (in our program referred to as the Course Associate) could reach out to the necessary parties to problem solve. During one particularly challenging class, the captionist simply did not show up and the office was closed. Our team creatively solved by having the Course Associate work as informal captionist through a text mechanism for the lecture, and expediting the video of the class for formal recorded captioning so that the student did not miss any critical information. This experience was critical in developing a disaster readiness plan for future classes should something like this occur again.

\section{Discussion}

\subsection{General Best Practices}

There is no one particular theory or instructional methodology that is recommended or cited as a 'gold standard' for educating $\mathrm{D} / \mathrm{d} / \mathrm{HH}$ students (Paul, 2009). In residential classrooms, best practices to support deaf and hard-of-hearing students include modifications to the physical space to reduce signal-to-noise ratios (Moeller, Tomblin et al., 2007) and to manage the interference from background noise. Specific to secondary and post-secondary settings, sign language interpreting and real time text have not been found to have one advantage over the other in supporting D/d/HH students, however, both are acknowledged as preferable to no communication support at all (Spencer \& Marschark, 2010). Many of the challenges are managed within the virtual learning space, as all students have equal 'seating' and in the online classroom, signal-to-noise ratios are often managed through the use of a student headset. It is important to work with the student, and if possible, the technology resource team so that the student can order a headset that will work most optimally with your synchronous platform (whether it is for student group meetings or for an online synchronous class).

Inclusion of $\mathrm{D} / \mathrm{d} / \mathrm{HH}$ students in online learning classes can be especially enhanced through the use of classroom-based technologies. Long, Vignare, Rappold, \& Mallory (2007) developed a 22 item questionnaire for D/d/HH and ESL students which asked them about their experiences as an online learner at a secondary education college. Students reported that they greatly benefited from online group discussions posting. Students shared their preference for using 
discussion boards for a number of reasons, including equal opportunity to share opinions and have one's digital opinion be heard, and that it added an interactive component between $\mathrm{D} / \mathrm{d} / \mathrm{HH}$ students and hearing students that was more challenging to facilitate in a synchronous learning environment. Overall, this study found that both $\mathrm{D} / \mathrm{d} / \mathrm{HH}$ and ESL (English Sign Language) students felt that online courses made communication with their peers and professors easier, as opposed to traditional in-class learning.

\subsection{Student Recommended Best Practices}

Based on multiple semester of collaboration with instructors and administrators through her higher education experience, [name redacted for blind review] has various recommendations for best practices when working with $\mathrm{D} / \mathrm{d} / \mathrm{HH}$ students include the following: when a professor learns of a $\mathrm{D} / \mathrm{d} / \mathrm{HH}$ student (or students) attending their course, it is suggested to check with the University's disability services department members, who have had the student in prior classes, to see what practices and preferences this student may require in the course, before placing burden on the student to explain their needs. Additionally, faculty should take the responsibility to reach out to that student prior to the start of the semester in order to do a "check-in" with the student regarding their needs in that specific class, to ensure that student has everything they need to be successful in that class, and as well as checking for any additional practices and preferences that may not have already been noted by their disability services department colleagues. Faculty should also reach out to the University's Office of Disability services or resource center to see what options for support are in place, and to have a professional staff member mine the syllabus and related course site for areas in which additional support may be needed.

It is suggested that all online course materials be checked for complete communications access (closed captioning, C-print, sign language interpretation) prior to uploading materials onto the course content page. It is not enough to rely upon YouTube or other informal captioning services, but to use formal and professional services provided through the University's disability services office. When possible, it is suggested that all communication access for $\mathrm{D} / \mathrm{d} / \mathrm{HH}$ students be checked, tested, and ready to be implemented prior to the day of the first online class. It is suggested that the professor of a course with $\mathrm{D} / \mathrm{d} / \mathrm{HH}$ students attending develop and prepare a communication policy and/or communication rules for hearing peers to read about interacting with $\mathrm{D} / \mathrm{d} / \mathrm{HH}$ learners, including overall policies for the entire classroom community and available prior to the first online class. The communication policy and/or rules can be created and approved by the disability services department of the college but should be inclusive of the perspective of at least one $\mathrm{D} / \mathrm{d} / \mathrm{HH}$ person. These policy/rules include, but are not limited to: access of communication services made on the campus' student disability services website, communication service options clearly presented to students with disabilities, and the campus' general policy against discrimination of students with disabilities.

\subsection{Role of the Instructor}

Spencer and Marschark (2010) call for the responsibility of course designers, a role often held by the instructor, to look across disciplines to look at convergent assumptions as well as convergent ideas and best practices. As shared in the case study, the instructor should always watch any captioned media to look for spelling or other interpretive mistakes before posting it online and be prepared to edit as necessary. Also, media should be selected at least 4 weeks in advance to allow for institutional captioning. If other students are sharing media as part of a presentation assignment, a required due date for media that accommodates this time line is critical for the inclusive learning experience.

For synchronous courses, instructors should have a back-up plan if a live captionist is unable to or does not show up for a session. There should be a clear plan outlined that will cover captioning, emergency contact information for the captioning team and if coverage is not possible, recording the lecture so that it may be captioned and sent to the student as soon as possible following the live class and necessary extensions on course assignments to address this barrier.

Successful teachers have been found to have both expertise in the subject matter being taught in the course and integrating it with the knowledge about the learning styles and learning patterns of students who are $\mathrm{D} / \mathrm{d} / \mathrm{HH}$ (Spencer \& Marschark, 2010). Some concrete examples of this include building in regular office hours to check for comprehension of course goals and objectives, challenging the assumption that Deaf/deaf and hard of hearing students can comprehend the primary spoken language of the course as well as Hearing students. While neither ASL interpreting nor real-time text has any generalized advantage over the other in supporting postsecondary $\mathrm{D} / \mathrm{d} / \mathrm{HH}$ students, both provide improved access when compared to no support (Spencer \& Marschak, 2010). Basic familiarity with the learning styles of $\mathrm{D} / \mathrm{d} / \mathrm{HH}$ students in residential and online settings, understanding pedagogy of building Deaf inclusive courses and inclusive evaluation techniques are recommended to deepen the classroom experience for $\mathrm{D} / \mathrm{h} / \mathrm{HH}$ students.

Finally, instructors need to be prepared to advocate for their students to challenge institutional barriers such as budget 
restraints around captioning and to serve as psycho-educators for administrators as to not place burden on the student who is already navigating a challenging system. Challenging pervasive myths regarding how $\mathrm{D} / \mathrm{d} / \mathrm{HH}$ students learn and process information is another critically important step in educating students, colleagues and institutional systems to create an inclusive online learning environment.

\section{Implications for Further Research}

It is clear from the significant gaps in research currently that the lived experience of $\mathrm{D} / \mathrm{d} / \mathrm{HH}$ students in postsecondary education, particularly online settings, needs to be studied more deeply. In addition to more case studies about innovative and inclusive teaching methods, focus groups with $\mathrm{D} / \mathrm{d} / \mathrm{HH}$ adult learners and postsecondary students and semi-structured interviews in qualitative studies would help instructors, administrators and course designers elevate the voices of $\mathrm{D} / \mathrm{d} / \mathrm{HH}$ students to create more inclusive online classrooms. Longitudinal studies that track the application process, entrance of and experience of $\mathrm{D} / \mathrm{d} / \mathrm{HH}$ students in online programs would deepen the understanding of these students and help identify risk and protective factors to increase the program completion rates.

Consistently using terms such as $\mathrm{D} / \mathrm{d} / \mathrm{HH}$ in research terminology, program development and published articles is also critical in adhering to current and PC language use for the general $\mathrm{D} / \mathrm{d} / \mathrm{HH}$ community, and would allow for $\mathrm{D} / \mathrm{d} / \mathrm{HH}$ students to feel more included in postsecondary learning and research. Further analysis of systemic and institutional barriers would also challenge current myths about the needs and learning methods of $\mathrm{D} / \mathrm{d} / \mathrm{HH}$ students and could create a stronger infrastructure to support $\mathrm{D} / \mathrm{d} / \mathrm{HH}$ online student success.

\section{Limitations}

As this paper is a case study based on the experience of two individuals in a particular classroom, it cannot be generalized to all teaching scenarios. Other limitations include the fact that this is not a formal research study in which the experience of DdHH students was compared between a residential classroom and the online classroom. Finally, the lack of overall research is a limitation to this topic and it is hoped that this article can help facilitate further research about this critically important topic.

\section{Conclusion}

It is the hope of these authors which reflects the collaboration of a hearing instructor and $\mathrm{D} / \mathrm{d} / \mathrm{HH}$ student's educational journey over four courses and three semesters of graduate study to deepen the conversation around meeting the needs of $\mathrm{D} / \mathrm{d} / \mathrm{HH}$ students in higher education in online learning settings, particularly synchronous platforms. In writing this case study, it has become clear that further collaboration between hearing and $\mathrm{D} / \mathrm{d} / \mathrm{HH}$ instructors, students, course designers and researchers is needed both to provide missing data and elevate the voices and lived experience of $\mathrm{D} / \mathrm{d} / \mathrm{HH}$ students to improve course delivery and improve conditions for learning in order to improve educational outcomes for all stakeholders involved.

\section{References}

Abrami, P. C., Bernard, R. M., Wade, C. A., Schmid, R. F., Borokhovski, E., Tamim, R., Surkes, M., Lowerison, G., Zhang, D., Nicolaidou, I., Newman, S., Wozney, L., \& Peretiatkowicz, A. (2006). A review of eLearning in Canada: A rough sketch of the evidence, gaps and promising directions. Canadian Journal of Learning and Technology, 32(3), 1-78. https://doi.org/10.21432/T2QS3K

Alamri, A., \& Tyler-Wood, T. (2017). Factors Affecting Learners with Disabilities-Instructor Interaction in Online Learning. Journal of Special Education Technology, 32(2), 59-69. https://doi.org/10.1177/0162643416681497

Albertini, J. A., Kelly, R. A., \& Matchett, M. K. (2011). Personal factors that influence Deaf college students' academic success. Journal of Deaf Studies and Deaf Education, 17(1), 85-101. https://doi.org/10.1093/deafed/enr016

Bissonnette, L. (2006). Meeting the evolving education needs of faculty in providing access for university students with disabilities. Retrieved from http://www.profetic.org/spip.php?article8126

Cruz, D., Rodriguez, Y., \& Mastropaolo, C. (2019). Perceived microaggressions in health care: A measurement study. PLOS ONE, 14(2), e0211620. https://doi.org/10.1371/journal.pone.0211620

Debenham, M. (2002). Computer-Mediated Communication (CMC) and disability support: addressing barriers to study. Retrieved 12 September, 2009 from http://www.techdis.ac.uk/index.php?p=3_10_17 
Di Iorio, A., Feliziani, A. A., Mirri, S., Salomoni, P., \& Vitali, F. (2006). Automatically producing accessible learning objects. Educational Technology \& Society, 9(4), 3-16.

Eisner, N. (2012). Engaging Deaf and Hard of Hearing Students in the School Library: A Handbook for Teacher-Librarian. Retrieved 1 September, 2019 from https://files.eric.ed.gov/fulltext/ED533125.pdf

Ferreiro-Lago, E., \& Osuna-Aced (2017). Factors affecting the participation of the Deaf and Hard-of-Hearing in e-Learning and their satisfaction: a quantitative study. International Review of Research in Open and Distributed Learning, 18(7), 267-291. https://doi.org/10.19173/irrodl.v18i7.2862

Fichten, C. S., Asuncion, J. V., Barile, M., Fossey, M. E., Robillard, C., Judd, D., \& Lamb, D. (2004). Access to information and instructional technologies in higher education: Disability service providers' perspective. Journal of Postsecondary Education and Disability, 17(2), 114-133.

Fichten, C. S., Ferraro, V., Asuncion, J. V., Chwojka, C., Barile, M., Nguyen, M. N., Klomp, R., \& Wolforth, J. (2009). Disabilities and e-learning problems and solutions: An exploratory study. Educational Technology \& Society, 12, 241-256.

Floyd, K., \& Santiago, J. (2011). The state of website accessibility in higher education. Proceedings of the 2007 Southern Association for Information Systems Conference. Retrieved 23 February, 2019 from http://www.maconstateit.net/kfloyd/papers/SAIS07-25\%20Floyd-Santiago.pdf

Long, G. L., Marchetti, C., \& Fasse, R. (2011). The importance of interaction for academic success in online courses with Hearing, Deaf, and Hard-of-Hearing students. The International Review of Research in Open and Distance Learning, 12(6), 1-19.

Long, G. L., Vignare, K., Rappold, R. P., \& Mallory, J. (2007). Access to communication for Deaf, Hard-of-Hearing and ESL students in blended learning courses. International Review of Research in Open and Distance Learning, 8(3), 1-13. https://doi.org/10.19173/irrodl.v12i6.1015

Marschark, M., Paivio, A., Spencer, L., Durkin, A., Borgna, G., Convertino, C., \& Machme, E. (2017). Don't assume Deaf students are visual learners. Journal of Developmental and Physical Disabilities, 29, 153-171. https://doi.org/10.1007/s10882-016-9494-0

Marschark, M., Lang, H., \& Albertini, J. (2002). Educating deaf students: From research to practice. New York, NY: Oxford University Press.

Myers, M. J., \& Taylor, E. M. (2000). Best practices for deaf and hard of hearing student success in postsecondary education. Journal of the American Deafness and Rehabilitation Association, 34, 13-2.

National Institute on Deafness and Other Communication Disorders (2016). Retrieved 1 September, 2019 from https://www.nided.nih.gov/

Newman, L., Wagner, M., Knokey, A-M., Marder, C., Nagle, K., \& Shaver, D., et al. (2011). The post-high school outcomes of young adults with disabilities up to 8 years after high school: A report from the National Longitudinal Transition Study-2 (Report No. NCSER 2011-3005). Menlo Park, CA: SRI International.

Paul, P. V. (2009). Language and deafness (4th ed.). Sudbury, MA: Jones and Bartlett Publisher.

Qi, S., \& Mitchell, R. E. (2007, April). Large-Scale academic achievement testing of Deaf and Hard-of-Hearing students: past, present, and future. Paper presentation at the Annual Meeting of the American Educational Research Association. Chicago, IL.

Richardson, J. T., MacLeod-Gallinger, J., McKee, B. G., \& Long, G. L. (2000). Approaches to studying in deaf and hearing students in higher education. Journal of Deaf Studies and Deaf Education, 5(2), 156-173. https://doi.org/10.1016/j.ridd.2016.04.004

Roberts, J., Crittenden, R., \& Crittenden, J. (2011). Students with disabilities and online learning: a cross-institutional study of perceived satisfaction with accessibility compliance and services. The Internet and Higher Education, 14, 242-250. https://doi.org/10.1016/j.iheduc.2011.05.004

Spencer, P. E., \& Marschark, M. (2010). Evidence-based practice in educating deaf and hard-of-hearing students. Professional perspectives on deafness, 1. Oxford University Press.

United States Department of Education (2019). Disability Discrimination: Overview of the Laws. Retrieved 23 February, 2019 from http://www.ed/gov/policy/rights/guid/ocr/disabilityoverview.html

United States General Services Administration (2019). Section 508 standards summary. Retrieved 23 February, 2019 
from http://www.section508.gov/index.cfm?fuseAction=stdsSum

\section{Copyrights}

Copyright for this article is retained by the author(s), with first publication rights granted to the journal.

This is an open-access article distributed under the terms and conditions of the Creative Commons Attribution license (http://creativecommons.org/licenses/by/4.0/). 